of the heat capacity and thermal insulation of concrete walls and floors, and routine analytical tests to determine cement contents of concrete and identify attacking agents. The instrument section provides facilities for the servicing of electrical apparatus and undertakes the design and construction for other departments of instruments which are not available from commercial sources.

The Concrete Department is devoted to the study of the materials for making concrete and to the examination of concrete-making techniques designed to provide specific properties in the final product.

The materials section has the general objective of improving the practice of preparation of aggregates and the design of concrete mixes. To this end it studies methods of testing aggregates and cement, and of assessing the qualities required of concrete as an engineering material. Systematic investigation has enabled the factors which cause variation in quality of concrete to be identified and measured, and has made it possible to design, from widely variable raw materials, mixes which will give concrete having desired properties.

The basic research of the materials section has provided the informed background for the work of the methods section, which examines special uses of concrete and concentrates on improvements in the technique employed. A detailed study has been made of the procedure for laying granolithic floor toppings and a fundamental investigation is being made of frost damage to concrete kerbstones. As part of this work the shrinkage and creep of concrete are being examined with novel apparatus, particular attention being paid to dimensional changes in the setting and hardening period.

The Structural Engineering Department is concerned with the improvement of design methods for concrete structures, improvement of the knowledge of the behaviour of concrete structures, development of new concrete structural forms, and the study of practical constructural problems. The design studies are carried on in close collaboration with other engineering research laboratories and with practising engineers. The Department is fortunate in having available a specially designed laboratory in which tests can be made on full-scale elements of structures or on models of a size which approaches full-scale. Testing is carried out with a large test frame, the base of which is the heavily reinforced floor of the laboratory, and loading is by means of hydraulic jacks. The performance of the structure under test is examined by mechanical and electrical strain ganges and can be recorded automatically.

A special study has been made of the design of shell roofs, of the effect of concentrated loads on bridge decks and of the properties of prestressed concrete structures. The Department has also been able to collaborate with engineers on actual con. struction, and much valuable information has been obtained relating the performance of laboratory models to that realized in the full-scale structure.

The Roads Department was formed to carry out research and development work on all forms of pavement construction in which cement is used. Its principal interest has been in concrete pavements, lean concrete bases and cement-stabilized soil bases. Experimental work has been carried out on techniques of road laying and of the details of road construction, such as joint making, repair and resurfacing. The Department maintains a close interest in road and airfield work in progress, and its services are extended to site control of unusual and/or particularly important projects. Advisory work is also undertaken for local authorities and others concerned with the building of new roads.

The basic function of the Works and Services Department is the provision of a service of craftsmen and labourers for carrying out all kinds of building operations. All departments call upon the services of this Department for routine maintenance of plant and property and for the carrying out of building experiments which involve the skill of tradesmen. The Department also carries out investigations in its own right and has been particularly interested in the development of attractive surface finishes for concrete. Some hundreds of examples of different surface finishes are undergoing weathering trials on the Station, and architects and others interested in applying them are provided with detailed instructions how to achieve the effects. A further substantial part of the various work of this Department is the organization of field work for training courses. Every year training course for about forty persons are held at roughly fortnightly intervals, and one of the functions of the Works and Services Department is to arrange full-scale demonstrations of various aspects of concrete technology ranging from simple batching trials to complete demonstration of prestressing techniques.

These training courses are organized by another division of the Cement and Concrete Association, but it was felt most appropriate to hold the courses where the research work is in progress. The success of the courses and the importance attached to communication of the fruits of research are underlined by the decision to provide two of the new buildings mainly for training purposes.

\section{RESEARCH COUNCIL OF ALBERTA}

\section{REPORT FOR 1956}

$T$ HE thirty-seventh annual report of the Researeh Council of Alberta*, which includes the usual lists of publications of the Council, members of committoes, and staff, covers the year 1956, in which the formal opening of the Council's new laboratories and pilot plant on a site adjacent to the University of Alberta was the outstanding feature. The Council's geological effort was further strengthened during the year, and two new advisory committees were established, one dealing with agricultural matters and the other with the problem of hail, commencing with a study of basic cloud physics in co-operation with the Meteorological Division of the Department of Transport.

Encouraging progress was made in coal research, the major effort of the organic chemistry laboratory being concerned with the constitution of humic acids and further studies of the pyrolysis of coal in presence of acid catalysts. Comparison of the infra-red spectra of humic acids, coals and synthetic coal-like substances prepared by oxidative polymerization of hydroquinone at high temperatures suggests that while the concept of a continuous inerease of rank in coals is sound, materials giving infra-red spectra typical of bituminous coal may be found in various ways. The Physical Chemistry Laboratory has studied the mechanism of pyrolysis of coal and the * Research Council of Alberta. Thirty-seventh Annual Report, 
solubility of partly carbonized coal. Palæobotanical studies have concentrated on fossil woods and spores, and the collection of modern conifer woods, begun in 1955, is now virtually complete. So also is the first stage of the fluidized coal carbonization programme begun in 1955 in co-operation with the University Department of Chemical Engineering, and it was anticipated that the equipment would be transferred to the Council's new pilot plant in the spring or early summer of 1957 . 'L'ests in Germany indicate that it is not possible to manufacture binderless briquettes of commercial quality from Alberta sub-bituminous coal in either extrusion-type or high-pressure ring-roll presses, but the possibility of using hot-briquetting processes is being explored in Europe.

Petroleum geochemistry is now recognized as the unifying theme in the work on petroleum, and the programme is being co-ordinated on this principle. Work continued on the porphyrin content of oil and its destruction in relation to the presence of vanadium, nickel and other trace elements. A detailed survey is being made of the occurrence of vanadium and nickel in the Pembina oil field with a view of following oil migration within the field, and the flow of Athabasca oil sand through a hopper is also being studied. Other work has been concerned with the characterization of the sulphur compounds in the oil-sands oil, and the selective oxidation of thiophenic acid sulphur by nitric acid. The hydrocarbon research programme deals with the mechanism of the uncatalysed pyrolysis of hydrocarbons and the decomposition of halo-hydrocarbons.

The work on natural gas has been reoriented, and yields of acetylene and ethylene in the range of com. mercial interest were obtained by pyrolysis of $n$-butane at about $250^{\circ} \mathrm{F}$. and atmospheric pressure, greater severity of cracking favouring the formation of acetylene. Particular emphasis is being placed on the engineering problems associated with the high heat load required for such pyrolytic reactions, and fundamental studies are being made on adsorption with reference to the use of such techniques in separating hydrocarbons.

The geological section is making excellent progress with its ground-water programme, and the surficial geology of the Hardisty-Killam-Kinsella area was mapped on a scale of one inch to one mile. A Cretaceous microfaunal study was completed in cooperation with the University of Alberta and a microfaunal research project on the Exshaw formation initiated. The clay fraction of shale samples collected across the contact of the non-marine Oldham formation and the marine Bearpaw formation is being studied by X-ray diffraction, and chemical analysis and detailed petrographic and stratigraphic studies of the Lower Cretaceous Blairmore formation of southern and central Alberta continued.

Reconnaissance oil surveys were made on 500,000 acres in the Blueberry Mountain sheet, and some 10 million acres were covered in the exploratory soil survey by helicopter from the Lesser Slave Lake to the Saskatchewan boundary. Additional data were accumulated, despite unusually heavy rainfall, in the co-operative irrigation research on solanetzic soils. The highway research programme included fundamental studies on the use of electro-osmosis to inject chemicals into soils of the texture of silts and finer, as well as on the use of chrome-lignin gels for soil stabilization and for the prevention of frost heaving in soils. Comprehensive laboratory tests were made on samples of soils taken from test-holes in areas of extensive slides which have occurred in the vicinity of the town of Peace River.

The industrial engineering services section is primarily a service group, but it undertook some investigations, including work in co-operation with the University Department of Agricultural Engineering on the utilization of butane in engines. Work in animal science included a study of the influence of the productive energy level of the ration in the reproductive performance and efficiency of turkeys, and a study of the nutritive value of rapeseed oil meal.

\section{HYDRO-ELECTRIC POWER IN THE U.S.S.R.}

$Y^{\prime} T$ is always a matter of interest to the Western world when the veil of secrecy surrounding many of the activities of the inhabitants of the U.S.S.R. is lifted a little. A report was presented to a joint meeting on May 20 of the Institutions of Civil, Electrical and Mechanical Engineers on the visit of six British engineers to the U.S.S.R. to examine the hydro-electric installations there. It is clear that their hosts spared no effort to provide these visitors with the information they desired, especially with regard to those parts of their vast territory which they were unable to visit. It is also refreshingly clear that the visitors were determined to supplement this information with the results of their own observations of the installations and factories seen. In so far as the use of electricity is a pointer to the progress of industrialization of a community, the report is of value in showing the position achieved by the U.S.S.R., and some interesting comparisons with Great Britain are possible. There is a great wealth of factual information given, which makes the report heavy reading, although correspondingly more valuable, and a fair summary of the report must also, therefore, be mainly concerned with facts.

At the present time the electricity generated in the U.S.S.R. per head of population is rather less than half the corresponding figure for Great Britain. This may be accounted for to some extent by the greater proportion of rural to urban population; but another contributory factor is the more extended use of combined steam-power stations, where the heat of combustion of the fuel is partly used to generate electricity and partly used to provide steam for industrial purposes and for space-heating. This dualpurpose type of station is more attractive economically in the U.S.S.R. than in Great Britain on account of the higher proportion of the urban population who live in large blocks of flats, and 30 per cent of the plant capacity of thermal stations is in combined stations.

The rate of growth of electricity consumption in the next five years is estimated at 45 per cent (9 per cent per annum) for Great Britain, and at 88 per cent for the U.S.S.R. If these rates of progress are maintained, the U.S.S.R. should consume more electricity per head than Great Britain by 1967. Of this total electricity generated, the proportion produced by hydro-electric power is 13.5 per cent at present but is estimated to approach 20 per cent by 1960 .

The potential hydro-electric power generation of the country is enormous, and has been estimated as 